\title{
Legislative Intent of the Noise Act with Respect to Traffic Noise Control
}

D. Potužníková ${ }^{1,2} *$, T. Hellmuth ${ }^{1}$, P. Junek ${ }^{1}$

${ }^{1}$ National Reference Laboratory for Communal noise at the Health Institute Seated in Ostrava, Czech Republic

*Corresponding author: dana.potuznikova@zuova.cz

P. Bednarčík

Faculty of Military Health Sciences, University of Defence, Hradec Králové, Czech Republic

Z. Fiala ${ }^{2}$

${ }^{2}$ Charles University in Prague, Faculty of Medicine, Hradec Králové, Institute of Hygiene and Preventive Medicine, Hradec Králové

DOI: $10.2478 / \mathrm{v} 10158-012-0034-\mathrm{z}$

\begin{abstract}
A bill on the protection of public health against noise and for noise control in the municipal environment ("Noise Act") has the character of a Codex due to the issue of noise control in the municipal environment affecting the competence of many departments. An effective solution to this problem requires not only a comprehensive legislative approach, but also the necessity of coordination. It is proposed to set up a National Council of Noise that would work within the Office of the Government. The bill is designed to maximally apply the principles of subsidiarity and shared responsibility. To control the health impact of traffic noise in the outdoor area the previous legally enforceable system of one-figure noise limits is being abandoned and a new noise zone system is proposed. The noise limits should be used in this instance in accordance with the practice in other European countries as an interval of values (zones), which will be respected in noise control. The emphasis for the protection of public health against noise is placed on the protection of the interiors of buildings for housing, education, health and social purposes, where the level of health risks is minimized by setting an obligatory noise limit, which is the same for all noise zones and all noise sources.
\end{abstract}

KEY WORDS: Noise, transport, noise control, impact of traffic noise.

\section{INTRODUCTION}

Noise is a serious detrimental factor of the human environment. Noise is intrusive, annoying and can cause harmful effects on the health of the exposed persons (Havránek et al., 1990; WHO, 2009; WHO, 2011). The problem of health protection and noise management in the environment is a typical interdisciplinary issue, the solution of which requires a coordinated approach and comprehensive legal regulation that does not exist in the Czech Republic up to now.

The Ministry of Health has prepared and submitted a bill on the protection of public health against noise and for noise control in the municipal environment ("Noise Act"). The bill is designed in accordance with the Policy Statement from the Government 
of the Czech Republic and Czech Government Resolution No. 69 of 26 January 2011 and was discussed within the framework of internal and interdepartmental amendment procedures.

As the problem of noise control in the municipal environment affects the competence of many departments, the bill has the character of a Codex. The strategic aim of the bill is to replace the existing obsolete system of population protection against noise in the municipal environment by setting new rules that would allow for solutions to problems that the existing legal regulation neither sufficiently permits nor resolves. It is important to overcome the current fragmentation in the field of legal enactments controlling noise in the municipal environment, and to propose a comprehensive legal regulation defining the competences and responsibilities of different departments in the field of the protection of public health against noise in the municipal environment. It is advisable to replace the existing paternalistic approach and delegate the appropriate authorities and responsibilities to different levels of state and public administrations, including individuals, on the principle of shared responsibility and subsidiarity.

Experience has shown that the current legislative approach does not satisfactorily solve the problems such as the question of so-called "old noise pollution", "noise capacity of areas" (prevention of the cumulative effect of different noise sources), sporadic or short-term exposure to over-the-limit noise. It has not yet been possible to establish an "acoustic easement" which would allow for a better solution to the problem of subsequent and conditional entry of persons (builders) into an exposed area.

It can be stated that harmonizing the law with legal regulations controlling town and country planning and construction relative to noise has not been satisfactorily resolved yet. (Construction Act and its implementing regulations).

An unsatisfactory situation is also found in the field of supervising road and railway traffic noise. Exceeding the noise limits can often be solved only by imposing sanctions which does not solve the underlying problem. The situation is frequently handled via timelimited authorizations.

\section{BASIC CLASSIFICATION OF NOISE SOURCES}

Requirements for noise control pollution in the municipal environment need to be distinguished by the character and impact of the noise on humans. It concerns, on the one hand, the area of protection of public health that means reducing or possibly eliminating the health risks resulting from the exposure to noise, and, on the other hand, the area of acoustic comfort. It is relatively easy to distinguish noise sources arising in these areas.

As for the protection of public health, the control of so-called technical noise sources, which means all types of transport noise and stationary noise sources such as machinery and equipment (industrial sources), plays a dominant role. In the case of acoustic comfort, it concerns the limitation of the general annoying and intrusive effects of noise that do not have a direct impact on health, but may lead to a deterioration in the quality of the lives of persons exposed. Noise disturbance and annoyance is caused primarily by random (stochastic) noise sources, which are mainly people's voices, acoustic manifestations of animals, neighborhood noise, public performance of music, sports, cultural and other leisure activities, etc.

The bill separates the regulation of technical noise sources and subordinates it to the State Health Supervision, and random noise sources. The effect of technical noise sources can jeopardize human health; random noise sources can cause acoustic discomfort through general disturbance and nuisance. The Bill on noise entrusts the responsibility for solving 
random noise sources to municipalities as is common in all other developed countries in Europe.

The emphasis in the field of the protection of public health against noise is put on the protection of interiors of buildings for housing, education, health and social purposes. Noise exposure in these areas, particularly in residential areas, has a decisive influence on human health. The health risks are in this case minimized by setting the binding hygienic noise limit which is the same for all noise zones and all technical sources.

\section{THE MAIN OBJECTIVES OF THE PROPOSED LEGAL REGULATION}

The main objectives of the proposed legal regulation can be summarized in the following points:

- Solve the current fragmentation in the field of noise legislation in the municipal environment;

- Propose a comprehensive legislation defining competencies and responsibilities of individual authorities in the protection of public health and noise control in the municipal environment;

- Replace existing paternalistic approach;

- Delegate authorities and responsibilities to each level of state and public administration, including the participation of citizens based on the principle of shared responsibility and subsidiarity;

- Exclude situations (exposures) which are not a direct threat to health from the state health supervision, because the state cannot guarantee good noise conditions in all cases and from all possible sources of noise, particularly in the case of random sources, voluntary exposure, etc.;

- Delegate competences of noise control to municipalities on the basis of acoustic comfort;

- Emphasize the responsibility of every citizen, designer and operator of noise sources for the general reduction of environmental noise;

- Establish central coordination in the field of noise control and management;

- Establish a professional coordinating and advisory body of the Government;

- Establish a regular blanket assessment of traffic noise load on CR citizens and corresponding health risks as a basis for the policy of noise management and noise control;

- Categorize noise sources based on their impact on people and to determine the competences of state administration and self-government in noise control in each category;

- Control of technical noise sources to be left as the responsibility of public health protection authorities;

- Control of stationary noise sources such as machinery, equipment, industrial complexes, etc. based on one-figure noise limits, both outside and inside the protected buildings;

- Control of noise sources based on acoustic comfort to be fully transferred to the responsibility of municipalities;

- Define a concept of sporadic or short-term exposure to noise and transfer responsibility to the municipalities;

- Resolve noise control from construction activities by setting organizational and technical measures where noise limits from the stationary sources would serve as guidelines; 
- Change the non-functioning system of environmental traffic noise control;

- Control the environmental traffic noise by abandoning the legally enforceable system of one-figure noise limits and set a system of noise zones representing intervals of socially acceptable levels of health risk;

- Set up a system of acquisition, approval, promulgation and changes of noise zones.

- Link strategic and operational approaches to noise control, including the obligation of action plans to be in compliance with the END directive;

- Integrate strategic noise mapping in the system of blank noise mapping of the Czech Republic;

- Set up responsibility of implementing and providing the action plans of noise control measures within the competence of relevant statutory persons (noise maker);

- Precisely define the term "hygienic noise limit";

- Establish health risk assessment within the state health supervision as is recommended by the World Health Organization (WHO) in analogy to the procedures used in the EU developed countries as an obligatory instrument for noise control;

- Introduce new tools into the legal regulation that it will allow for the flexible cumulative effect, old noise pollution, shared noise measures by property owners, etc.;

- Introduce the possibility of acoustic easement where the property owner may partially or completely reject noise control measures proposed by a noise maker.

\section{TRAFFIC NOISE CONTROL PROPOSAL}

A necessary condition for enabling reduction and noise control in the municipal environment is an introduction of central coordination in the field of noise control and management, including regular surveys of the Czech Republic's population who are burdened by traffic noise (which accounts for $80 \%$ of the overall noise burden of the population) and the assessment of the related health risks. The proposed extended version of the strategic noise mapping, based on the implemented directive 2002/49/EC of the European Parliament and of the Council dealing with assessment and environmental noise control (Environmental Noise Directive - END), has been running since 2005 (Official Journal of the European Communities, 2002). The END directive implemented into Act No. 258/2000 Coll., on the protection of public health, as subsequently amended, established the strategic noise mapping and produced action plans for noise control measures. However, the national amendment does not solve the duty of putting these action plans and policies into effect. The Noise Act should align strategic and operational approaches to noise control, including a binding force of action plans under the END directive, incorporating strategic noise mapping into the system of blank noise mapping of the Czech Republic. Moreover, authorized persons (noise makers) should be obliged to implement action plans into the system of noise control measures.

To control the impact of environmental traffic noise, the legally enforceable system of one-figure noise limits is abandoned. The limits would be used in accordance with the practice in other European countries as guidelines that should be respected in noise control. However, there is concern that the concept of non-binding noise limits will not be fully functional in the Czech Republic, which in other countries is respected and successfully used without any problem. So it is necessary to formulate an obligation to control traffic noise in the environment in another way. The Noise Act therefore introduces an institute of noise zones in conformity with the approach of many European countries. The zones represent the extent of values tiered according to a level of health risk. In the Noise Act, the four zones (A, B, C, D) are proposed which are defined for day 
and night time and for each traffic noise source. The zone A represents the lowest load, zone $\mathrm{D}$ the highest. The noise zone boundary is chosen in the interval of the socially acceptable level of health risks of exposure to noise. The requirements for an adequate level of protection against noise are defined in each zone. The appropriate level of protection shall be provided at expenses of a person (builder) who enters in a given area with his/her property (building). The noise zones are defined on the basis of calculated noise maps which are created by the competent government authority and become an integral part of the planning analytical materials. The design of noise zone categories and their meaning is presented in Table 1.

Table 1: Design of noise zones and their meaning.

\begin{tabular}{|c|l|}
\hline Designation & \multicolumn{1}{|c|}{ Description of noise zones } \\
\hline A & $\begin{array}{l}\text { Noise need not be considered as a determining factor in granting a permit } \\
\text { for the intended project for the construction of protected buildings. }\end{array}$ \\
\hline B & $\begin{array}{l}\text { Noise shall be considered in determining the intended project } \\
\text { for the construction of protected buildings or sources of traffic noise and, } \\
\text { where appropriate, shall be subjected to prescribed conditions (noise } \\
\text { protection measures may be applied). }\end{array}$ \\
\hline C & $\begin{array}{l}\text { Granting a permit for the intended project is not guaranteed. Where } \\
\text { the permit is considered to be granted, for example, because no other } \\
\text { suitable sites for the construction of protected buildings or sources of traffic } \\
\text { noise are available. The prescribed conditions have to be met to ensure } \\
\text { an adequate level of protection against noise (noise protection measures } \\
\text { have to be applied). }\end{array}$ \\
\hline D & $\begin{array}{l}\text { Permission for the intended project for the construction of protected } \\
\text { buildings is commonly rejected. }\end{array}$ \\
\hline
\end{tabular}

The Bill proposes to update the traffic noise zones every 5 years, which means at intervals in accordance with the END directive (Official Journal of the European Communities, 2002).

The institute of protective noise zone of airports and rules for the determination of its boundaries and operating mode are amended.

The submitted legislative intent of the Noise Act envisages the implementation of health risk assessment, as recommended by the World Health Organization (WHO) as the binding instrument of noise control (WHO, 2012; European Environment Agency, 2010). Methodologies are known in the Czech Republic and authorized persons for the health risk assessment of noise exposure use them as standard operating procedures (Potužníková et al., 2012). 


\subsection{Responsibilities of Owners and Operators of Roads and Railways}

Owners of roads and railways are obliged to ensure that noise shall not exceed the hygienic health limits of noise inside the protected buildings. They are also obliged to comply with the noise zones of roads and railways in built-up and non-built-up areas of municipalities. Operators of noise sources are required to get an expert opinion on noise levels in protected areas and on possible noise control measures in Zone D. Such opinions may be included in the action plan for noise control measures.

The operators are required to design and implement noise control measures to minimize the extent of noise in zones $\mathrm{D}$ based on the action plans, i.e. to reduce the exposure of protected outdoor areas. These measures should be based on the principle of a reasonably achievable rate so as to reduce the maximum number of protected buildings located in this noise zone.

For existing residential buildings, family houses, buildings for education and training, buildings for health and social care and functionally similar buildings located in the noise zone $\mathrm{D}$, the operator must ensure the implementation of noise control measures to the extent that hygienic noise limits shall not exceeded inside the protected buildings. Urban, organizational measures and noise control measures protecting outdoor areas are preferred to noise control measures inside each protected building.

The operator of the source of traffic noise is not responsible for the above mentioned obligations in the protected buildings the construction of which has been initiated after the declaration of noise zones. In these cases the responsibility belongs to the builder of protected buildings.

If it is proved that sound insulation no longer meets the original standard value due to the poor technical condition of the building envelope, the responsibility belongs to the property owner.

In case the traffic intensity spontaneously increases after the expiry date of this Bill, which leads to the need to change (update) the declared noise zones, or the original standard values of airborne sound insulation of protected building envelopes shall no longer be satisfactory, the operator of the traffic noise source together with the owner of the protected property are responsible for the implementation of subsequent noise control measures.

\subsection{Responsibilities of Airport Operators}

The airport operator is obliged to ensure that noise from air traffic related to the particular flight day shall not exceed hygienic noise limits inside the protected buildings. Furthermore, he is obliged not to undermine the boundaries of noise zones for air traffic noise in built-up areas of municipalities. The operator of the military airport and the airport with 50,000 or more take-offs and landings shall provide the action plan for noise control measures in the noise zones $\mathrm{C}$ and $\mathrm{D}$ at his own expense. Particulars of the action plan for noise control measures shall be applied similarly to the above mentioned measures of the operators of traffic noise source. For protected buildings located in the noise zones $\mathrm{C}$ and $\mathrm{D}$, the operator is obliged, on the basis of the action plan, to ensure the implementation of noise control measures to such an extent that the noise limits are not exceeded inside these buildings. The operator is required to design and implement measures to minimize the spatial extent of zone $\mathrm{D}$ on the principle of a reasonably achievable rate so as to reduce the maximum number of protected buildings located in this noise zone.

This obligation does not have an operator for residential buildings the construction of which is commenced after the date of declaration of the noise zones. In these cases, the liable party is the builder. 
If it is proved that the insulation no longer meets the original standard value due to the poor technical condition of the building envelope, the liable party is the property owner.

In the D noise zone for air traffic noise new construction of buildings for health, social, educational and training purposes is not permitted.

\section{CONCLUSION}

The legislative intent of the Act on the protection of public health from noise and for noise control in the municipal environment represents a completely new approach to health protection against noise compared to the current legal regulation in the Czech Republic. It is based on the WHO expert documents, approaches in providing health protection in the European countries and also on many years of experience of the Ministry of Health, particularly the Hygienic service, in this area. In view of the fact that this is a new professional and comprehensive legislative approach, consultations with experts from other ministries, processing of comments and communication with the public are an integral part of work on the Bill. Based on the above mentioned, the draft will be further refined and the professional and general public will be familiarized with the new approaches.

This article is based on the legal intent of the Noise Act and the explanatory report.

\section{ACKNOWLEDGEMENTS}

Supported by program:

- PRVOUK P37/09, Charles University in Prague, Faculty of Medicine in Hradec Králové

- A long-term organization development plan 1011”, Faculty of Military Health Sciences, University of Defence, Hradec Králové

\section{REFERENCES}

European Environment Agency, 2010. Good practice guide on noise exposure and potential health effects, technical report, No. 11/2010. Bonn: WHO, pp. 14-15. ISSN 1725-2237.

Havránek, J. et al., 1990. Hluk a zdraví. Praha: Avicenum. ISBN 80-201-0020-2. (in Czech)

Official Journal of the European Communities, 2002. Directive 2002/49/EC of the European parliament and of the council of 25 June 2002 relating to the assessment and management of environmental noise. Official Journal of the European Communities, 1. 189/12, 18.7.2002.

Potužníková, D., Hellmuth, T., Bednarčík, P., Fiala, Z., 2012. Zkušenosti z hodnocení zdravotních rizik expozice hluku ze silniční dopravy [Experience in the health risk assessment of exposure to noise from road traffic]. Hygiena, 57 (3), pp. 100-104. (in Czech)

WHO, 2009. Night Noise Guidelines for Europe [online]. Denmark: World Health Organization, Regional Office for Europe [cited 2013-07-23]. ISBN 9789289041737. Retrieved from: http://www.euro.who.int/pubrequest 
WHO, 2011. Burden of Disease from Environmental Noise [online]. [cited 2013-07-23]. ISBN 97892890 02295. Retrieved from: http://www.euro.who.int/pubrequest

WHO, 2012. Methodological Guidance for Estimating Burden of Disease from Environmental Noise. Regional Office for Europe [online]. [cited 2013-07-23]. Retrieved from: http://www.euro.who.int/pubrequest 